\title{
Estâncias de criação de gado e cativos em Rio Pardo no final do Século XIX
}

\author{
Livestock ranches and slave labor in Rio Pardo in the late 19th century \\ Estancias ganado y cautivos en Rio Pardo a finales del siglo XIX
}

Olgário Vogt ${ }^{*}$

Bruna Vieira Spenner*

\section{Resumo}

O objetivo do artigo é analisar a composição do patrimônio de estâncias de criação de gado em Rio Pardo, RS, no final do Século XIX e detectar em que medida a força de trabalho escravo esteve presente nas atividades pastoris. Como foco de análise foram selecionadas as estâncias Nossa Senhora da Vitória e das Pederneiras, dois dos principais empreendimentos criatórios do município. A principal fonte empírica de pesquisa utilizada é constituída de fontes primárias manuscritas. Trata-se dos inventários post mortem de Mathias José Velho, proprietário da Santa Vitória, e do vereador José Ferreira Porto, dono das Pederneiras.

Palavras-chave: Estâncias de gado. Escravidão. Inventários post mortem.

\section{Introdução}

No Rio Grande do Sul (RS), prevalece, no senso comum, a tese de que a escravidão teria sido pouco expressiva e branda na Província. A historiografia tradicional em muito contribui na construção desse pensamento equivocado. Apenas para exemplificar, Souza Docca (1954, p. 81) escreveu que foi insignificante a contribuição do sangue africano na formação do tipo sul-rio-grandense. Arthur Ferreira Filho (1974, p. 140) defendeu que o RS, quando comparado com as demais províncias brasileiras, apresentava reduzido

* Olgário Vogt, professor do Curso de História e do Programa de Pós-graduação em Desenvolvimento Regional da UNISC.

** Bruna Vieira Spenner, mestre em desenvolvimento regional; arquiteta e urbanista.

Recebido em 01/04/2014 - Aprovado em 25/06/2014 http://dx.doi.org/10.5335/hdtv.14n.2.4581 
número de cativos, não encontrando a escravidão "ponto de apoio do temperamento liberal dos gaúchos." Na mesma toada, Amyr Borges Fortes registrou que o RS

[...] foi, das províncias brasileiras, uma das que recebeu menor número de escravos, pois, desde logo, ficou evidenciado que os negros africanos não se ambientavam ao clima do sul do pais e, ainda, que os misteres da criação não eram bem desempenhados por esses indivíduos. Utilizados apenas nos labores domésticos e nas charqueadas, em nenhuma província como na nossa, encontraram, os escravos, tratamento mais clemente e humano. Raramente eram submetidos a espancamentos e castigos corporais, e frequentes eram as alforrias concedidas por ocasião de festas, aniversários etc. (FORTES, 1962, p. 93-94).

O escravo, mesmo quando admitida sua incorporação nas estâncias, teve ofuscada sua marcante presença pela ideologia da democracia pastoril. Assim, em 1927, Jorge Salis Goulart (1978, p. 11) defendeu que na estância duas forças combinadas, o meio físico e o trabalho pastoril imposto pela natureza do solo, atuaram para irmanar patrões e empregados, sendo o gaúcho muito mais um amigo do que um subordinado de seu patrão. Laços de intimidade democrática e de unidade afetiva uniam, em um latifúndio, donos de estâncias, seus parentes e peões (GOULART, 1978, p. 28-29). Trabalhando ombro a ombro com seu senhor, o cativo teria recebido um tratamento mais humanitário e digno que em outras atividades. Como pontua, com propriedade, Mário Maestri (2008, p. 184), a ideologia da democracia pastoril procurou escamotear "contradições sociais essenciais no seio das unidades pastoris e, assim, na antiga formação social sulina".
O emprego da força de trabalho escrava nas lides campeiras já foi tema de acalorados debates. Mesmo autores de fundamentação teórica marxista negaram, ou ao menos minimizaram o envolvimento de cativos nesse tipo de atividade. Nesse sentido, Paulo Xavier (1969, p. 78) dividiu os trabalhadores das estâncias entre os realizados por homens livres e os realizados por homens escravizados. De forma idêntica, classificou os ramos da economia estancieira em dois grupos: a mercantil e a natural. Os cativos estariam ligados ao ramo da economia natural. Parcela deles se dedicaria à lavoura, plantando e elaborando a riqueza indispensável para o consumo da unidade produtiva. Outra parte desenvolveria um artesanato doméstico produzindo sabão, queijos, linguiças, conservas, tecidos, rendas e outros mais. Já os trabalhadores livres - agregados e peões - estrariam ligados ao ramo da economia mercantil. Seriam supervisionados diretamente pelo estancieiro ou o seu preposto, o capataz, se constituindo em uma espécie de trabalhadores servis.

O campeiro, com sua família, ocupa trechos da terra; neles constrói o seu rancho, planta e colhe produtos para seu próprio consumo. O gozo desses benefícios será jungido à sua fidelidade ao dono da terra. Alguns capatazes ou agregados mais capazes e úteis recebem animais - terneiros - por ocasião das marcações, como prêmio aos seus préstimos e interesse demonstrado pelo trabalho. Seus filhos são "afilhados" do patrão. Sua fidelidade torna-se cada vez mais de natureza servil. O estancieiro é o protetor de todos os dependentes de sua área e sobre todos exerce autoridade indiscutível (XAVIER, 1969, p. 78). 
Dessa forma, Xavier caracteriza a estância como uma combinação de uma economia natural com a mercantil, respectivamente sob o regime escravista e servil, e exclui o escravo no envolvimento direto dos trabalhos com o gado. Francisco Riopardense de Macedo (1969, p. 115) defendeu tese análoga a de Xavier ao afirmar que as estâncias eram centros comunais onde escravos e um punhado de homens livres aplicavam-se a dois tipos de economia: a natural e a mercantil.

Décio Freitas (1983) sustentou que, desde o início, na estância gaúcha preponderaram relações capitalistas de produção. A massa de trabalhadores rurais das estâncias teria sido composta de homens juridicamente livres que, não possuindo a nenhum título os meios de produção, vendiam sua força de trabalho para prover a subsistência. O emprego do escravo na atividade pastoril não era recomendado por dois motivos. Um deles está relacionado à supervisão e à vigilância do cativo.

No pastoreio, haveria que colocar um feitor ao lado de cada escravo pastor, já que sem a vigilância e a supervisão este último obviamente trabalharia pouco e mal, usando com toda a probabilidade o cavalo para fugir através das distâncias, indivisas e despovoadas campanhas, cruzando a raia em busca de uma liberdade assegurada legalmente nas terras platinas. Semelhante vigilância e supervisão seria logicamente antieconômica (FREITAS, 1983, p. 28).

O outro motivo pelo qual não se recomendava a utilização do escravo na atividade pastoril é o fato de que os africanos não dominavam a técnica do trabalho. Teriam, portanto, que ser adestrados para a execução das tarefas. Nesse sentido, seria antieco- nômico importar negros da África e submetê-los a um longo aprendizado. Mais lógico seria recrutar "uma massa de trabalhadores livres dotada de experiência e tradição pastoris: os gaúchos ou gaudérios, índios e mestiços" (FREITAS, 1983, p. 28).

A obra pioneira de Fernando Henrique Cardoso, de 1962, contestou a tese da escravidão branda, evidenciou a importância dos trabalhadores cativos nas charqueadas e apontou para a utilização da mão de obra escrava nas estâncias do RS. Trabalhos investigativos recentes confirmaram que a escravidão permeou, de alto a baixo, a sociedade sul-rio-grandense e destacaram que a força de trabalho escrava foi empregada em diferentes regiões da Província, inclusive na criação e na lida do gado.

Paulo Zarth (1997, 2002), ao pesquisar a história agrária na região do planalto, no norte do Estado, na segunda metade do Século XIX, fundamentado em uma amostragem de inventários, demonstrou a forte presença da escravidão naquela região. Destacou que nas estâncias rio-grandenses foi significativa a escravidão, sendo ela "bem mais importante do que a historiografia tem divulgado" (ZARTH, 2002, p. 149). Ali, os grandes estancieiros recorreriam com regularidade ao trabalho cativo.

Fábio Kühn, em tese de doutorado defendida em 2006, deixou consignado que os primeiros lagunenses que se instalaram nos Campos de Viamão depois do primeiro terço do Século XVIII se valiam do trabalho escravo africano e também indígena. A partir do rol dos confessados de 1751, constatou que "mais de $45 \%$ da população era cativa, um percentual muito elevado, semelhante 
ao encontrado nas zonas mineradoras ou de plantation e não muito adequado a uma região voltada ao mercado interno" (KÜHN, 2006, p. 110). Apurou, ainda, que pelo censo paroquial de 1778, dois terços dos fogos de Viamão apresentavam a existência de escra$\operatorname{vos}(K U ̈ H N, 2006$, p. 130).

Helen Osório, investigando o final do período colonial do RS, a partir de inventários post mortem, constatou que $97 \%$ dos estancieiros da sua amostragem eram proprietários de cativos. Averiguou que nas estâncias que possuíam de 101 a 1.000 cabeças de gado, a escravaria compunha $29,9 \%$ do patrimônio produtivo; já naquelas de mais de 1.000 cabeças de gado, integralizavam 17,3\% do montante (OSÓRIO, 2007, p. 107). Significativa parcela desses trabalhadores compulsórios seriam domadores e campeiros.

Luís Augusto Farinatti (2010, p. 357) diagnosticou que nos campos do Alegre os escravos campeiros "eram maioria nas escravarias pertencentes aos grandes estancieiros e marcavam presença também nos extratos inferiores da hierarquia econômica dos criadores de gado." Verificação idêntica seria depois feita por Marcelo Santos Matheus (2012) para aquela área de fronteira; por Maria Beatriz Eifert (2007) nas fazendas pastoris de Soledade e por outros.

Esses e tantos outros trabalhos, revisitando antigas ou incorporando novas fontes, ecoam no extremo sul do país a renovação da historiografia a respeito dos trabalhadores e da escravidão que ocorre no Brasil desde a década de 1980 (CHALHOUB; SILVA, 2009). No entanto, é inimaginável tratar a respeito do trabalhador escravo no RS sem mencionar os historiadores Mário Maestri e Paulo Roberto Staudt Moreira. Ambos, embora se valendo de enfoques teórico-metodológicos distintos, por meio dos seus incontáveis escritos e pelos pós-graduandos por eles orientados, têm contribuído significativamente para o avanço de pesquisas sobre a temática.

Contudo, apesar desses significativos avanços historiográficos e apesar de sua importância na formação social e econômica do Brasil meridional, não se encontra ainda uma história geral sobre a estância pastoril sulina (MAESTRI, 2008, p. 176). Ao mesmo tempo, são ainda parcos os estudos monográficos sobre as características da população escrava nas áreas de pecuária extensiva e sobre as atividades que, realmente, realizavam no complexo estancieiro (FARINATTI, 2010, p. 348).

O presente artigo se propõe problematizar a presença do trabalhador cativo em atividades pastoris. Em razão da importância histórica de Rio Pardo na formação do território do RS e pela importância que teve o gado na sua economia, foi tomado como locus da pesquisa. O período escolhido foi o do final do segundo Império, época em que a atividade criatória do RS estava no auge, mas já apresentava visíveis sinais de esgotamento (HERRLEIN JR., 2000). Consoante com objetivos da pesquisa, optou-se trabalhar com os dois principais empreendimentos então ali existentes: a Estância Nossa Senhora da Santa Vitória e a Estância das Pederneiras. 


\section{A fonte primária utilizada e o objeto de} pesquisa

Rio Pardo foi um importante centro escravista no Século XIX. Em 1872, conforme os dados do censo demográfico então realizado, havia, na Paróquia, 2.509 cativos. Conforme demonstrou Melina Perussatto (2010), em sua dissertação de mestrado, nas décadas finais da escravidão, o trabalho cativo estava disseminado por praticamente todas as atividades e espaços produtivos. Detectou, pelos inventários compulsados, que a participação dos proprietários que detinham a posse de trabalhadores escravos atingira a marca de $70,1 \%$ entre os anos de 1860 e 1887 (PERUSSATTO, 2010, p. 52).

Dentre os 286 proprietários de escravos inventariados por Perussatto (p. 64) ao longo de 27 anos, predominavam os proprietários de pequenos planteis (donos de 1 a 9 trabalhadores cativos) que perfaziam $83,1 \%$ dos escravistas. Os médios (donos de 10 a 20) e os grandes proprietários (donos de mais de 20 escravos) representavam somente $1 / 6$ dos escravistas. No entanto, juntos, possuíam mais da metade $(50,6 \%)$ da posse de cativos.

Nesse sentido, visando diminuir a escala para permitir uma análise micro do objeto de estudo, mas sem divorciá-lo do contexto maior em que está inserido, optou-se por dissecar os inventários dos dois principais estancieiros de Rio Pardo no final do segundo Império: Mathias José Velho e José Ferreira Porto.

Inventários são documentos judiciais feitos após a morte de um indivíduo. Através desse os bens do falecido são partilhados entre seus herdeiros, conforme prevê a legislação da época e de acordo com a vontade do morto, caso tenha firmado um testamento. Para o pesquisador, os inventários podem se constituir em importantes testemunhos da vida material e cultural de indivíduos e de grupos sociais do passado (FURTADO, 2009). Os inventários do Século XIX quase sempre descrevem, pormenorizadamente, os bens de herança móveis (objetos, instalações profissionais, estoques, créditos e valores mobiliários), imóveis (propriedades rurais e urbanas) e semoventes (referente a escravos e animais) de um indivíduo, dívidas ativas e passivas e os bens alheios encontrados no espólio do inventariado (DAUMARD et al, 1984, p. 176-179). Por meio desses, é possível "avaliar tanto a riqueza de um grande estancieiro como o grau de pobreza de um pequeno posseiro" (ZARTH, 2011, p. 20). Pelo número e valor dos móveis e utensílios de uso cotidiano inventariados, a própria vida doméstica pode ser aquilatada pelo pesquisador (FLEXOR, 2009, p. 27).

Os inventários normalmente são constituídos de três partes distintas. Na primeira parte, aparecem dados pessoais do falecido e a relação dos herdeiros; na segunda, há a descrição e a avaliação dos bens móveis, imóveis, semoventes e as dívidas ativas e passivas deixadas pelo falecido; na terceira é feita a partilha dos bens entre os herdeiros.

A base empírica principal utilizada neste texto é constituída pelos inventários post mortem dos seguintes estancieiros: Mathias José Velho, proprietário da Estância da Santa Vitória, falecido em 25 de maio de 1875, cujo inventário iniciou em 8 de março de 1876 e foi concluído em 1879; José Ferrei- 
ra Porto, proprietário da Estância das Pederneiras, falecido em 29 de dezembro de 1881, cujo inventário iniciou em1882 e foi concluído em 1885.

Essas fontes documentais primárias foram localizadas no Arquivo Público do Estado do RS. O inventário de Mathias José Velho encontra-se no Fundo 007, Comarca de Rio Pardo, Subfundo Vara Cível e Crime. O inventário do vereador José Ferreira Porto encontra-se no Fundo 004, Comarca de Porto Alegre, Subfundo $1^{\mathrm{a}}$ Vara da Família e Sucessão. Os inventários, após localizados, foram digitalizados. Por se tratar de documentos manuscritos, de leitura relativamente difícil, os dados relativos às estâncias foram transcritos para possibilitar uma análise mais atenta.

\section{Estância Nossa Senhora da Vitória}

A Estância Nossa Senhora da Vitória, também conhecida como Estância da Vitória, está localizada às margens do rio Jacuí e da rodovia BR 471, a qual liga Rio Pardo a Pantano Grande. Antes de pertencer a Mathias José Velho, o desembargador Pedro Rodrigues Chaves foi seu proprietário. Esse a vendeu para Velho em 29 de dezembro de 1857 (SPENNER, 2013, p. 82). Pedro Rodrigues Chaves, a partir de 1855, passou a ostentar o título de Barão de Quaraí, razão pela qual o empreendimento foi chamado, durante algum tempo, de Estância do Barão de Quaraí. Chaves foi, também, liderança expressiva do Partido Conservador, Senador do Império e Presidente da Província da Paraíba, vindo a falecer em 1866 em Toscana, Itália (LAYTANO, 1979).
A família Mathias Velho foi uma das mais ricas do RS na segunda metade do Século XIX, possuindo inúmeras propriedades rurais e urbanas espalhadas pela Província de São Pedro, sendo a Estância Nossa Senhora da Vitória apenas uma delas. Mathias José Velho nasceu em Mostardas, em 1792, e morreu em Rio Pardo, em 1875. Casou, em 1827, com Luciana Francisca da Terra, nascida em 1806 e falecida em 1888 (SPENNER, 2013). O inventário pesquisado tem data inicial de 1876 e foi finalizado somente em 1879. A demora aconteceu pelo fato de o inventariado ter herdeiros menores de idade. O casal morava na Estância da Vitória quando Velho veio a falecer. Deixou como herdeiros sua esposa e 11 filhos.

Com base nos relatos feitos por Macedo (1969), Pinto (1989) e Laytano (1979), e a partir de descrições existentes no inventário, foi possível elaborar a Figura 1, em que se procura demarcar a área aproximada da estância no ano de 1876. 
Figura 1 - Área de terra inicial da Estância Nossa Senhora da Vitória

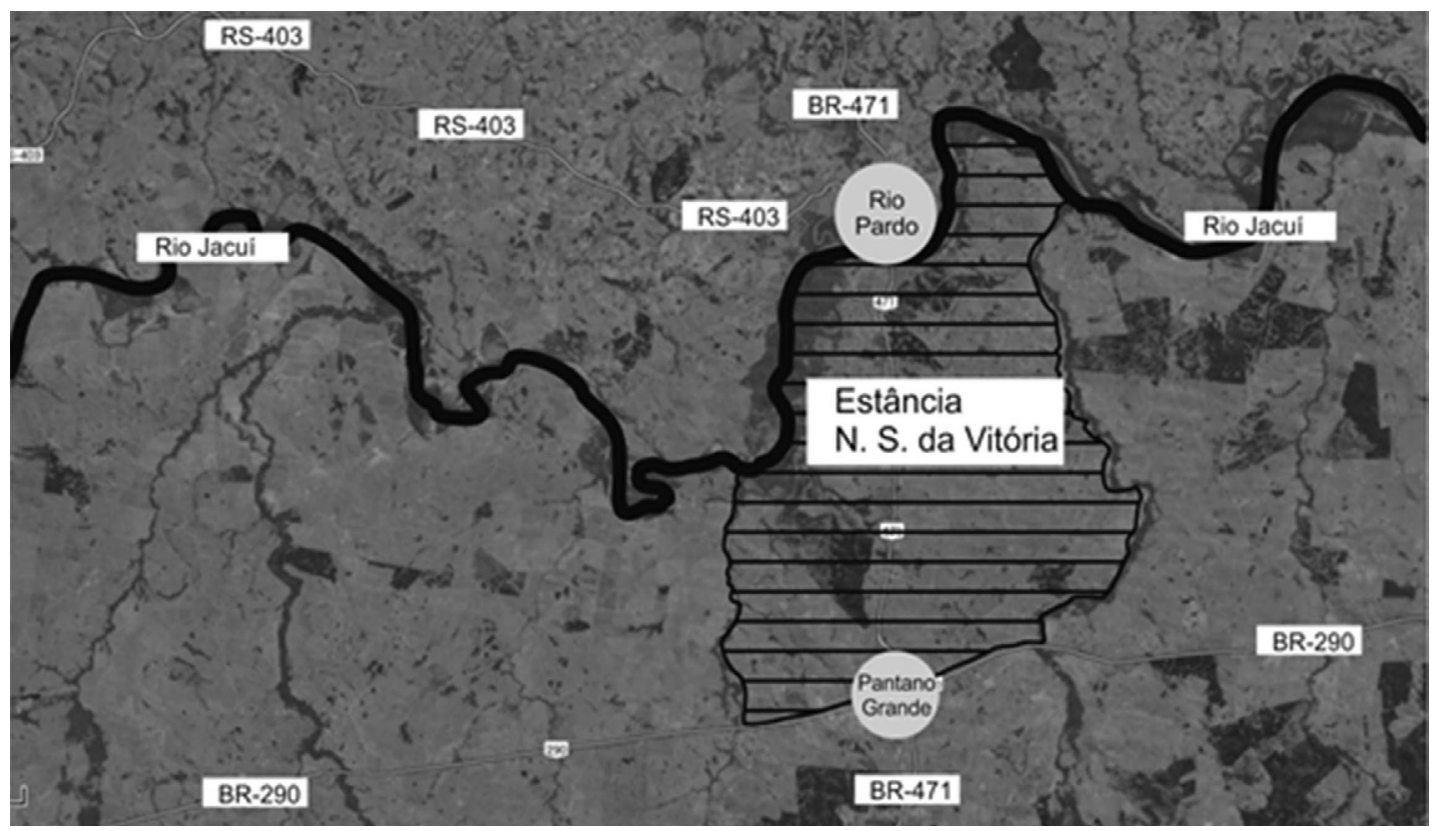

Fonte: Elaborado pelos autores a partir dos dados do inventário de Mathias José Velho.

A Estância Nossa Senhora da Vitória tinha em torno de oito léguas de campo correspondendo a, aproximadamente, $35 \mathrm{mil}$ hectares. Essa propriedade constituía um grande patrimônio, ao qual se somavam as demais benfeitorias, os animais, a casa-sede e os muitos utensílios e móveis ali existentes. As oito léguas de campo então pertencentes à estância estão demarcadas na Figura 1. Para se ter uma noção do tamanho dessa área, nos dias atuais, ela compreende toda a extensão da rodovia BR 471, da ponte sobre o rio Jacuí até a cidade de Pantano Grande, uma distância de cerca de 25 quilômetros. Quando ocorrida a distribuição de sesmarias, usava-se os arroios e os rios como forma de limitar as terras. E na ilustração da área da Estância Nossa Senhora da Vitória são perceptíveis os limites com o rio Jacuí e os arroios Capivari, Dom Marco e Tabatingaí.
Com as heranças e desmembramentos ocorridos posteriormente, a área original da estância teve significativa redução de extensão. Apesar das partilhas ocorridas, atualmente, ela ainda permanece com uma área de terras em torno de 1.500 hectares.

Considerada uma das mais importantes e uma das maiores do Século XIX em Rio Pardo, essa estância ainda preserva grande parte das edificações existentes no final do Século XIX. Tanto a casa principal como as demais estruturas que compõem a fazenda estão em ótimo estado de conservação. Ali também podem ser encontrados inúmeros móveis e utensílios da época de seu esplendor. Separada da cidade de Rio Pardo pelo rio Jacuí, ali podem ser encontrados vestígios da senzala, estatuetas, uma imagem de Nossa Senhora da Vitória, bancos de azulejo, chafarizes e outros. 
No inventário consta uma descrição detalhada dos bens de Mathias José Velho. Por ser um homem abastado, seu patrimônio estava espalhado por diferentes regiões da Província. Nesta pesquisa, foram coleta- dos apenas os dados referentes à Estância da Vitória. Na tabela 1, está a relação dos animais que havia na unidade produtiva no ano de 1876. No total, havia 15.032 animais, divididos da seguinte forma:

Tabela 1 - Quantidade e valor dos animais da Estância Nossa Senhora da Vitória - 1876

\begin{tabular}{l|r}
\hline \multicolumn{2}{c}{ Inventário de Mathias José Velho 1876 - Estância da Vitória } \\
\hline \multicolumn{1}{c}{ Descrição dos animais } & \multicolumn{1}{c}{ Valor } \\
\hline 11.544 reses de criar xucras & $126: 984 \$ 000$ \\
312 ditas mansas & $4: 056 \$ 000$ \\
305 novilhos & $5: 490 \$ 000$ \\
121 bois mansos & $2: 662 \$ 000$ \\
179 cavalos mansos $1^{\text {a }}$ qualidade & $3: 222 \$ 000$ \\
106 cavalos mansos $2^{-}$qualidade & $954 \$ 000$ \\
67 potros capões & $804 \$ 000$ \\
24 mulas mansas & $5756 \$ 000$ \\
1066 éguas xucras & $4: 264 \$ 000$ \\
1300 ovelhas & $1: 950 \$ 000$ \\
8 burros & $24 \$ 000$ \\
\hline Total & $150: 986 \$ 000$ \\
\hline
\end{tabular}

Fonte: Inventário de Mathias Jose Velho.

Para a execução dos trabalhos diários de campo, a estância tinha 53 cativos. Dentre esses, 35 escravos eram do sexo masculino, dos quais 16 campeiros, 2 roceiros, 1 pedreiro e um ferreiro. As escravas possivelmente eram responsáveis por atividades domésticas e artesanais no complexo da estância. Nem todos os escravos da estância listados no inventário aparecem com seus respectivos ofícios, conforme pode ser observado na Tabela 2. 
Tabela 2 - Listagem dos escravos da Estância Nossa Senhora da Vitória

\begin{tabular}{|c|c|c|c|}
\hline \multicolumn{2}{|r|}{ Descrição dos ESCRAVOS } & \multirow{2}{*}{$\begin{array}{l}\text { Profissão } \\
\text { campeiro }\end{array}$} & \multirow{2}{*}{$\begin{array}{l}\text { Valor } \\
1: 500 \$ 000\end{array}$} \\
\hline 1 & Cijumpio & & \\
\hline 2 & Braz & campeiro & $1: 200 \$ 000$ \\
\hline 3 & Adao Bambino & campeiro & $500 \$ 000$ \\
\hline 4 & Maria Victoria e o ingênuo & & $1: 000 \$ 000$ \\
\hline 5 & Rafael filho desta & & $100 \$ 000$ \\
\hline 6 & Frederico & campeiro & $1: 800 \$ 000$ \\
\hline 7 & Zeferino Juca & campeiro & $1: 500 \$ 000$ \\
\hline 8 & Jasé Passarinho & campeiro & $1: 200 \$ 000$ \\
\hline 9 & Paulo & campeiro & $1: 500 \$ 000$ \\
\hline 10 & Martinho & campeiro & 1:000\$000 \\
\hline 11 & Januário & campeiro & $1: 000 \$ 000$ \\
\hline 12 & Jacintho & campeiro & $1: 200 \$ 000$ \\
\hline 13 & Manoel, mulato & campeiro & $1: 600 \$ 000$ \\
\hline 14 & Roque & campeiro & $1: 000 \$ 000$ \\
\hline 15 & Davi & campeiro & $800 \$ 000$ \\
\hline 16 & Juliao & campeiro & $1: 200 \$ 000$ \\
\hline 17 & Clementino & campeiro & $800 \$ 000$ \\
\hline 18 & Conrado & & $500 \$ 000$ \\
\hline 19 & Luzia Genoveva & & $1: 000 \$ 000$ \\
\hline 20 & Jorge & & $600 \$ 000$ \\
\hline 21 & Antonio Meira & roceiro & $800 \$ 000$ \\
\hline 22 & Joao Meira & campeiro & $800 \$ 000$ \\
\hline 23 & Anturo & & $300 \$ 000$ \\
\hline 24 & José Crioulo, doente & & $25 \$ 000$ \\
\hline 25 & Julião & roceiro & $1: 500 \$ 000$ \\
\hline 26 & Pedro, mocambique & & $400 \$ 000$ \\
\hline 27 & Domingos & & $25 \$ 000$ \\
\hline 28 & Joaquim & pedreiro & $800 \$ 000$ \\
\hline 29 & João, cego & & $25 \$ 000$ \\
\hline 30 & Pio & & $400 \$ 000$ \\
\hline 31 & Julia e os ingênuos & & $1: 200 \$ 000$ \\
\hline 32 & Alfredo, filho da mesma & & $300 \$ 000$ \\
\hline 33 & Honoreia, filha da mesma & & $150 \$ 000$ \\
\hline 34 & Gertudi & & $900 \$ 000$ \\
\hline 35 & Cesária & & $1: 000 \$ 000$ \\
\hline 36 & Luciana Lucia e a ingênua & & $1: 200 \$ 000$ \\
\hline 37 & Gabriela, filha da mesma & & $100 \$ 000$ \\
\hline 38 & Ignes de Castro & & $1: 000 \$ 000$ \\
\hline 39 & Priciliana & & $1: 200 \$ 000$ \\
\hline 40 & Idalina e o ingênuo & & $1: 000 \$ 000$ \\
\hline 41 & Alexandre, filho da mesma & & $100 \$ 000$ \\
\hline 42 & Vicência & & $600 \$ 000$ \\
\hline 43 & Joaquina & & $800 \$ 000$ \\
\hline 44 & Virgilina & & $1000 \$ 000$ \\
\hline 45 & Bernarda & & $500 \$ 000$ \\
\hline 46 & Marcolina & & $300 \$ 000$ \\
\hline 47 & Romana & & $200 \$ 000$ \\
\hline 48 & Luisa, congo & & $700 \$ 000$ \\
\hline 49 & Joana & & $600 \$ 000$ \\
\hline 50 & Guilherme & & $800 \$ 000$ \\
\hline 51 & Mathias & & $500 \$ 000$ \\
\hline 52 & Joaquim & ferreiro & $500 \$ 000$ \\
\hline 53 & Antonio, congo & & $300 \$ 000$ \\
\hline Toté & & & $41: 025 \$ 000$ \\
\hline
\end{tabular}

Fonte: Inventário de Mathias José Velho. 
Nos inventários normalmente aparece os nomes dos cativos, sua idade, o sexo e valor. Por vezes, também estado de saúde origem e ofício dos cativos eram registrados. Esses dados todos, no entanto, não aparecem no inventário compulsado.

Nas áreas pastoris, os escravos campeiros e domadores valiam mais, pois eram fundamentais para a lida no campo e responsáveis por guardar e realizar os rodeios do gado. Osório (2005) levanta a hipótese de que o elevado preço dos escravos poderia ser uma forma dos estancieiros mantê-los em suas propriedades, sem que pudessem comprar sua alforria. Como o inventário pesquisado é de 1876, os valores dos escravos ainda são relativamente elevados. Logo em seguida seriam afetados pelo iminente fim escravidão.

A partir dos dados fornecidos pelo inventário, uma rés de criar xucra custava $11 \$ 000$ e um escravo campeiro de boa qualidade em torno de 1:500\$000. Sendo assim, eram necessárias cerca de 136 reses para comprar um bom escravo campeiro. Era um custo relativamente alto, porém o custo-benefício deveria valer a pena. Se o escravo trabalhasse por 10 anos, custaria 13,5 reses por ano, uma média de 1,2 reses por mês. Porém, há de se considerar que o cativo poderia ter uma vida produtiva muito superior a 10 anos. Obviamente que nesse cálculo não está computado o custo de manutenção do cativo que incluía alimentação, moradia e vestuário.

Embora possivelmente os escravos exercessem funções múltiplas no complexo de uma estância, tomando apenas os dados do inventário, teríamos um escravo campeiro para aproximadamente 940 animais.
Na descrição dos bens arrolados, aparecem também os móveis existentes na estância que incluía desde bandejas de prata, talheres, mobílias de jacarandá e mogno, até material de lida no campo. Analisando os bens descritos, é perceptível a fortuna dos proprietários. Um item chama atenção: os $3.681 \mathrm{~kg}$ de arame de ferro listados, o que denuncia a presença de alambrados. Isso significa que os campos passavam a ser cercados com arame. As cercas divisórias deram fim aos campos indivisos, diminuindo a necessidade de força de trabalho na lida com o gado (FRANCO, 1969 , p. 70-71). Os cercamentos iniciaram pelas estâncias mais abastadas a partir da década de 1870, "preparando o caminho para à melhoria dos rebanhos, à seleção das raças, à comercialização regular das tropas, e bem assim à sedentarização e à diminuição da peonagem" (CÉSAR, 2005, p. 137).

Com base nos dados coletados do inventário de Mathias José Velho, foi possível elaborar a Tabela 3.

Tabela 3 - Participação dos diferentes bens de produção no patrimônio da Estância Nossa Senhora da Vitória em 1876.

\begin{tabular}{l|r}
\hline \multicolumn{1}{c|}{ Bens de Raiz } & \multicolumn{1}{c}{ Valor } \\
\hline Escravos & $41: 025 \$ 000$ \\
Móveis e equipamentos & $4: 399 \$ 095$ \\
Animais & $150: 986 \$ 000$ \\
Terras (8 léguas) e casas & $320: 000 \$ 000$ \\
\hline Total & $516: 410 \$ 095$
\end{tabular}

Fonte: Inventário de Mathias José Velho

A partir dos dados da tabela é possível calcular a composição do patrimônio produtivo da estância. Em 1876, os animais representavam 29,23\%; os escravos 7,94\%; os móveis e equipamentos $0,85 \%$; e a terra 
as demais benfeitorias $61,97 \%$ do patrimônio produtivo total da estância. A terra se constituia então no bem mais valioso do estanciero. A valorização fundiária ocorreu principalmente a partir de 1850, quando foi editada a Lei de Terras.

\section{Estância das Pederneiras}

A Estância das Pederneiras está localizada às margens do rio Jacuí e da estrada denominada Passo das Pederneiras. No final do Século XIX, se localizava no $5^{\circ}$ distrito de Rio Pardo, denominado Capivary. Posteriormente, o distrito de Capivary foi denominado de Capivarita. A partir 1987, o distrito passou a integrar o município de Pantano Grande. De acordo com o inventário pesquisado, em 1882 a estância possuía em torno de oito léguas de campo, algo próximo a $35 \mathrm{mil}$ hectares. Com as informações coletadas no inventário, testamento e medição, foi possível elaborar um mapa aproximado da localização do empreendimento criatório.

Figura 2 - Área de terras da Estância das Pederneiras em 1882

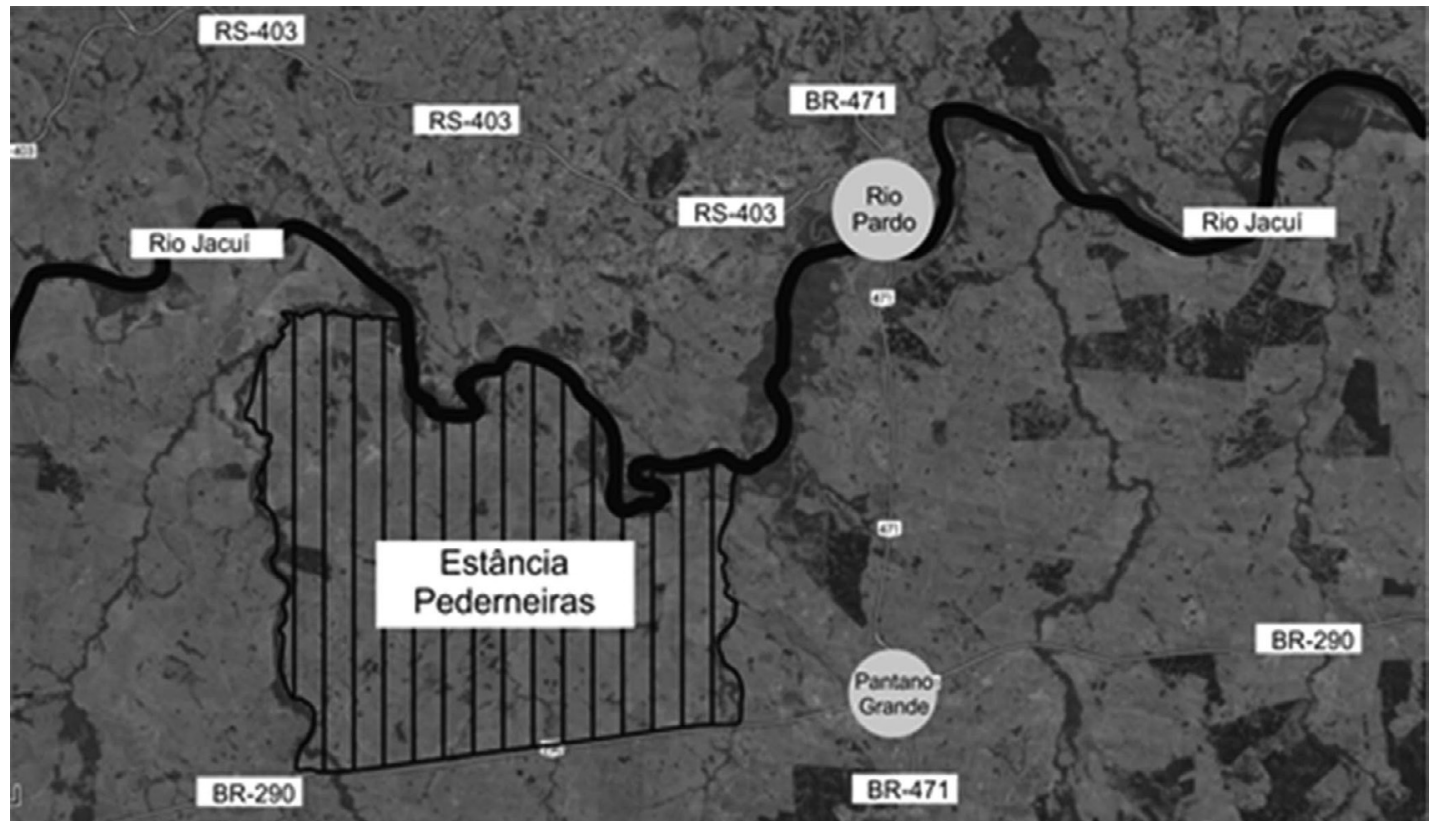

Fonte: Elaborado pelos autores a partir dos dados do inventário do vereador José Ferreira Porto.

Por meio da ilustração, percebe-se que a propriedade possuía grande parte de suas terras ao norte delimitadas pelo rio Jacuí. Do lado leste, fazia divisa com a propriedade dos herdeiros de José Mathias Velho, então proprietários da Estância Nossa Senhora da Vitória, que foi descrita anteriormente, e que possuía praticamente a mesma superfície territorial.

A estância pertencia à família Ferreira Porto, muito importante e rica na Província. Os Ferreira Porto possuíam títulos de nobreza em sua linhagem e eram grandes detentores de propriedades no RS. Conforme 
Macedo (1969, p. 117), a Estância das Pederneiras foi adquirida em 1780 pelo português Francisco Veloso Rebelo. Possivelmente os herdeiros de Veloso Rebelo a venderam para a família Ferreira Porto antes de 1865. $\mathrm{O}$ Conde $\mathrm{D}^{\prime} \mathrm{Eu}$, em sua primeira passagem pela província, referiu-se à propriedade da seguinte forma "Pelo espaço de nove léguas consecutivas fomos sempre contornando, a esquerda, as propriedades de um único indivíduo, o Sr. Ferreira Porto, vulgarmente conhecido por Portinho" (D`EU 1981, p. 38).
De acordo com o inventário de José Ferreira Porto, no que tange especificadamente à Estância das Pederneiras, nela estava lotada um plantel de 18 escravos. Os cativos tinham idades que variavam entre os quatro e os quarenta anos, sendo 13 do sexo masculino e cinco do feminino. Doze dos escravos arrolados tinham o ofício de campeiro, três eram domésticas, havendo, ainda, três ingênuos.

Tabela 4 - Escravos da Estância das Pederneiras em 1882

\begin{tabular}{l|l|l|c|c}
\hline \multicolumn{2}{c|}{ Descrição dos escravos } & Profissão & Idade & Valor \\
\hline 1 & Felippe & campeiro & 40 & $800 \$ 000$ \\
2 & Pampeu & campeiro & 15 & $900 \$ 000$ \\
3 & Ciriaco & campeiro & 36 & $600 \$ 000$ \\
4 & Gerlado & campeiro & 22 & $800 \$ 000$ \\
5 & João Antonio & campeiro & 18 & $800 \$ 000$ \\
6 & Estacio & campeiro & 32 & $400 \$ 000$ \\
7 & Felicidade & doméstica & 35 & $400 \$ 000$ \\
8 & Laura & & 14 & $600 \$ 000$ \\
9 & Zenobia & & 7 & $600 \$ 000$ \\
10 & Frutuosa & campeiro & 37 & $500 \$ 000$ \\
11 & Leonel & campeiro & 24 & $800 \$ 000$ \\
12 & Marcellino & campeiro & 23 & $600 \$ 000$ \\
13 & João Paulo & doméstica & 26 & $800 \$ 000$ \\
14 & Felicidade Benigma & & 4 & $500 \$ 000$ \\
15 & Andre & campeiro & 21 & $600 \$ 000$ \\
16 & Pedro & campeiro & 9 & $600 \$ 000$ \\
17 & Praxedes & campeiro & 40 & $500 \$ 000$ \\
18 & João do ceu & & $800 \$ 000$ \\
\hline Total & & & $11: 600 \$ 000$ \\
\hline
\end{tabular}

Fonte: Inventário do vereador José Ferreira Porto.

As campanhas pelo fim da escravidão no Brasil ocorridas na segunda metade do Século XIX afetaram o valor do escravo, como é possível notar quando se comparam os preços dos trabalhadores cativos do inventário de Ferreira Porto com o de Mathias José Velho. Como registrado acima, no inventário de Velho um bom escravo campeiro foi avaliado entre 1:500\$000 e 1:800\$000. Já na Estância das Pederneiras, o cativo campeiro foi ava- 
liado, no máximo, em 900\$000, o que sugere uma desvalorização do escravo num período de apenas seis anos. A média do valor dos escravos caiu de $772 \$ 170$ para $644 \$ 444$ de um inventário para outro. Enquanto em 1876 eram necessárias 136 reses para comprar um bom escravo campeiro, em 1882 eram necessárias apenas 69 reses de criar.

Noguerol et al. (2010), fundamentados em inventários pesquisados, construíram um gráfico do preço médio de escravos na Província do RS e no município de Bagé. Para tanto, elegeram como padrão os chamados escravos de primeira linha. Para eles, os escravos de primeira eram aqueles que apresentavam as seguintes características: ser sadio, do sexo masculino e contar de vinte a trinta anos de idade. A Figura 3 representa a variação dos preços médios desse tipo de cativo no Rio Grande do Sul e em Bagé ao longo de noventa anos.

Figura 3 - Variação dos preços dos escravos em Bagé e no RS

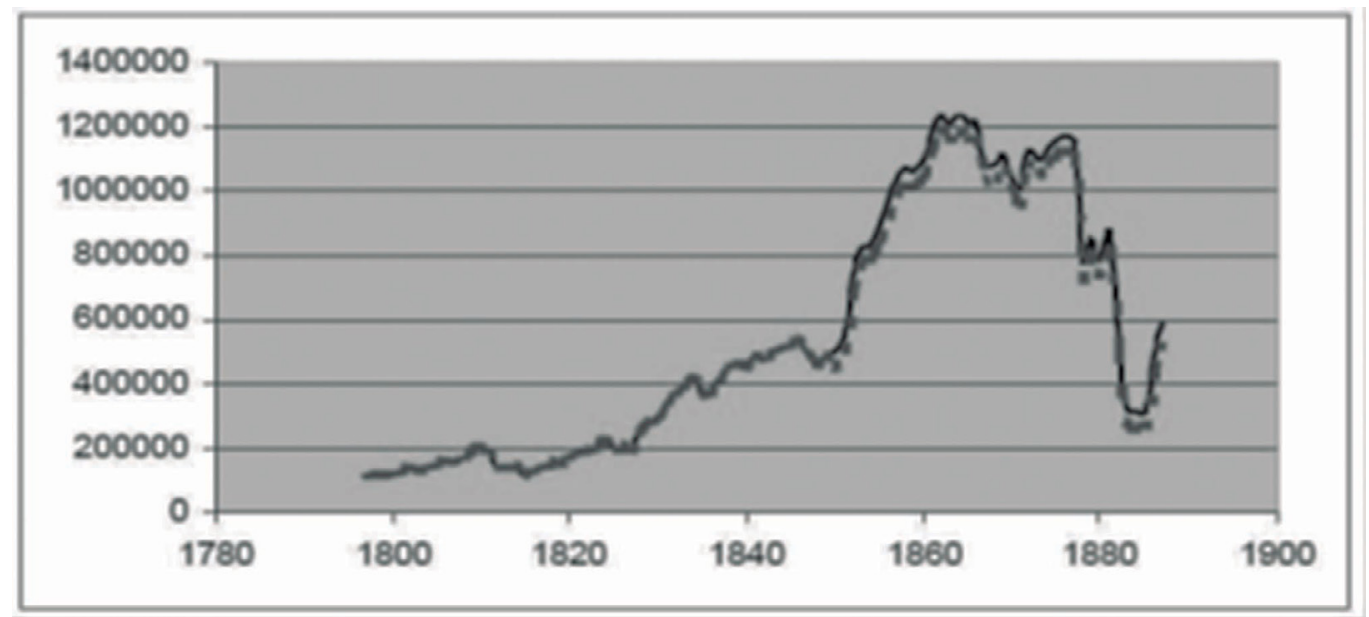

Fonte: Noguerol et al (2007) http://www.anpec.org.br/encontro2007/artigos/A07A025.pdf.

No arrolamento dos animais da Estância das Pederneiras é feita menção à presença da raça inglesa. São indícios da melhoria da qualidade genética dos animais e da existência de alambrados. A proprieade pos- suía 17.085 reses de criar, no valor de $13 \$ 000$ cada uma. Enquanto o valor do escravo decrescia com a proximidade do fim da escravidão, o valor da rês aumentava. 
Tabela 5 - Animais existentes na Estância das Pederneiras em 1882

\begin{tabular}{l|r}
\hline \multicolumn{1}{c|}{ Descrição dos animais } & \multicolumn{1}{c}{ Valor } \\
\hline 01 touro de raça inglesa & $500 \$ 000$ \\
01 cavalo dito & $1: 500 \$ 000$ \\
17.085 reses de gado de criar & $222: 105 \$ 000$ \\
970 reses de novilho & $25: 220 \$ 000$ \\
121 bois mansos & $3: 630 \$ 000$ \\
3655 éguas & $10: 965 \$ 000$ \\
18 mullas & $575 \$ 000$ \\
23 jumentos & $34 \$ 500$ \\
76 potros xucros & $912 \$ 000$ \\
56 potros de criação & $896 \$ 000$ \\
320 cavalos mansos & $5: 120 \$ 000$ \\
658 ovelhas & $987 \$ 000$ \\
83 novilhos de raça inglesa & $2: 158 \$ 000$ \\
35 potros de raça inglesa & $700 \$ 000$ \\
\hline Total & $275: 302 \$ 500$ \\
\hline
\end{tabular}

Fonte: Inventário do vereador José Ferreira Porto.

Essa estância, além do gado vacum, também se dedicava à criação de equinos. Ao todo, os animais da unidade somavam 23.102 cabeças. A partir daí, é possível calcular a porcentagem da lotação animal por hectare. Tomando por base que uma légua de campo corresponde a 4.356 hectares e que a estância era constituída de 8 léguas, chega-se ao seu tamanho aproximado, que deveria ser em torno de 34.848 hectares. Disso resulta uma lotação de 0,66 animais por hectare ou 2.888 cabeças de gado por légua de campo. Mas há que se considerar que nem toda a área deveria ser utilizada para apascentar o gado. Uma estância precisaria ter um pomar, uma roça para desenvolver a agricultura, benfeitorias construídas, áreas de matas.

Comparando a lotação da Estância das Pederneiras com a da Nossa Senhora da Vitória percebe-se que a primeira apresentava índices mais positivos. Na Estância da Vitória havia 1.879 animais por légua de terra e uma lotação de 0,43 animais por hectare. $O$ conde D’Eu (1981, p. 38) anotou que em 1865, nos arredores de Rio Pardo, uma légua quadrada poderia sustentar três mil reses de gado vacum. E Cezimbra Jacques (2000, p. 79) registrou que nas estâncias podia-se "criar folgadamente numa légua quadrada de campo, de 1.500 a duas mil cabeças de gado."

No que tange à proporção existente entre trabalhadores escravos e quantidade de gado, esta era de 1 campeiro cativo para 1.424 cabeças de animais na Estância das Pederneiras.

Como a unidade produtiva possuía mais que uma residência dentro de seus campos, elas foram avaliadas separadas do valor da terra. Esse fato não ocorreu com a estância estudada anteriormente em que apenas constava o valor dos campos com a casa.

Tabela 6 - Valor dos campos e benfeitorias da Estância das Pederneiras

\begin{tabular}{l|r}
\hline \multicolumn{1}{c|}{$\begin{array}{c}\text { Descrição das terras e } \\
\text { Benfeitorias }\end{array}$} & \multicolumn{1}{c}{ Valor } \\
\hline 8 léguas de campo & $240: 000 \$ 000$ \\
1 casa de sobrado & $5: 000 \$ 000$ \\
1 dita térrea morada do & $4: 000 \$ 000$ \\
capataz, peões e cocheiros & \\
1 casa térrea denominada & $1: 500 \$ 000$ \\
a Perdeneiras & $250: 500 \$ 000$ \\
\hline Total
\end{tabular}

Fonte: Inventário do vereador José Ferreira Porto.

Conforme a Tabela 6, cada légua de campo foi avaliada em 30:000\$000. O sobrado citado é a atual casa-sede da Estância da Quinta; já a casa térrea, denominada Pederneiras, constituía a casa-sede da Estância das Pederneiras. 
A partir desses dados, é possível chegar à composição do patrimônio produtivo dessa unidade criatória.

Tabela 7 - Avaliação dos bens produtivos do patrimônio da Estância das Pederneiras

\begin{tabular}{l|r}
\hline \multicolumn{2}{c}{ Bens de Raiz } \\
\hline Escravos & $11: 600 \$ 000$ \\
Equipamentos & $1: 310 \$ 000$ \\
Animais & $275: 302 \$ 500$ \\
Terra (8 léguas) & $240: 000 \$ 000$ \\
Benfeitorias & $10: 500 \$ 000$ \\
\hline Total & $538: 712 \$ 500$ \\
\hline
\end{tabular}

Fonte: Inventário do vereador José Ferreira Porto.

Com todos os bens relacionados, chega-se ao valor final do patrimônio da Estância das Pederneiras. Em 1882, ela foi avaliada em 538:712\$500. Um valor bem próximo da estância anteriormente analisada. As tabelas explanadas são de suma importância para o entendimento da composição do patrimônio produtivo da estância, que era assim integralizado: $2,15 \%$ de escravos; $2,19 \%$ de equipamentos; $51,10 \%$ de animais e $44,55 \%$ de terras e benfeitorias. Nessa estância o bem mais valioso eram os animais, diferentemente da estância da Nossa Senhora da Vitória onde a terra era o bem principal.

\section{Trabalhadores das estâncias: cativos e livres}

De uma forma geral, os estudos que tratam da relação entre trabalho escravo e capitalismo afirmam existir uma contradição insuperável entre esses.
A crença de que o trabalho escravo dificulta ou mesmo impede a melhoria dos processos produtivos permeia a quase totalidade das obras dedicadas à formação da economia brasileira (Castro, 2011, p. 231).

O trabalho cativo aparece como arcaico, ineficaz, pouco produtivo e pouco rentável quando comparado com o trabalho assalariado. Seria, mesmo, incompatível com as inovações tecnológicas e a divisão racional do trabalho. A concepção de que o trabalho do escravo é de qualidade inferior ao trabalho livre tem sua origem mais respeitável nos escritos de Adam Smith. Em seu trabalho seminal, A riqueza das Nações, publicado em 1776, ele expôs que:

[...] a experiência de todas as épocas e nações demonstra que o trabalho executado por escravos, embora aparentemente custe apenas a própria manutenção dos escravos, ao final é o mais caro de todos. Uma pessoa incapaz de adquirir propriedade não pode ter outro interesse senão comer o máximo e trabalhar o mínimo possível. Se algo ela fizer, além do suficiente para pagar a própria manutenção, só o fará se isso a beneficiar pessoalmente, sendo impossível obrigá-la a fazer esse algo mais sob violência (SMITH, 1983, p. 328).

Conforme Antônio Penalves Rocha (2000, p. 195), no que diz respeito ao trabalho escravo, a Economia Política defendeu que tendo o homem a liberdade e a propriedade de si mesmo, agiria sob o impulso de seus interesses, tornando-se mais ativo e inventivo, ao mesmo tempo em que administraria frugalmente sua vida. Inversamente, com a ausência da liberdade e da propriedade de si mesmo, isso é, na escravidão, o homem não teria motivação para o que quer que fosse, seria preguiçoso, não seria inventivo e desejaria sempre comer muito e trabalhar pouco. 
Em uma linha completamente oposta, o economista francês Jean-Baptiste Say, em seu Tratado de Economia Política, obra cuja primeira edição veio à luz no ano de 1803, procurou demonstrar que o trabalho escravo era mais barato e produtivo do que o trabalho livre. Partiu, para tanto, da seguinte proposição: "não tenho dúvida alguma de que [a escravidão] aumenta muito" a produção "ou pelo menos, que com o trabalho do escravo o excedente dos produtos sobre o consumo é maior do que com o trabalho do homem livre" (SAY, apud ROCHA, 2000, p. 182).

Nessa perspectiva, Say afrontava Smith, Turgot e Stuart Mill. Construiu, nesse sentido, uma explicação singular sobre a escravidão que contrariou tudo o que havia sido escrito anteriormente sobre o tema dentro da Economia Política e que destoou das concepções que foram defendidas ou adotadas posteriormente (ROCHA, 2000, p. 181). Por ser militante antiescravista e pelas críticas que recebeu de economistas contemporâneos seus, nas edições posteriores do seu Tratado de Economia Política, principalmente a de 1826, que foi a derradeira e que serviu de matriz para as reedições posteriores, abrandou suas concepções sobre a maior produtividade do trabalho escravo quando comparado ao livre e passou a fazer uma severa crítica econômica da escravidão (Rocha, 2000). Ainda assim, encontra-se na sua obra derradeira a seguinte passagem:

Os que pensam que o trabalho do escravo é menos dispendioso do que o do servidor livre fazem um cálculo semelhante ao seguinte: a manutenção anual de um negro nas Antilhas, nas habitações em que são mantidos com mais humanidade, não custa mais de 300 francos. Acrescentamos a isso juro de seu preço de compra e estimemo-lo em $10 \%$, pois se trata de um juro perpétuo. O preço de um negro comum sendo de 2 mil francos, mais ou menos, o juro será de 200 francos, calculado por cima. Assim, pode-se estimar que cada negro custa, por ano, 500 francos a seu senhor. Ora, num mesmo país, o trabalho de um homem livre custa mais do que isso. Pode cobrar por sua jornada de trabalho uma base de 5, 6 ou 7 francos e às vezes até mais. Tomemos 6 francos como média e só contemos 300 dias de trabalho por ano. Isso dá, como soma de seus salários anuais, 1.800 em vez de 500 francos (SAY, 1983, p. 197).

Os dados obtidos por meio dos inventários consultados evidenciam que nas grandes estâncias de criação de gado de Rio Pardo, na segunda metade do Século XIX, houve a conjugação do emprego da força de trabalho livre com a escrava, com a predominância da primeira.

Em suas pesquisas, Zarht (2002, p. 112) concluíra que "nas grandes estâncias, é certo que existiam escravos; nas pequenas ou médias, nem sempre." No mesmo sentido, Osório (2007) constatou que já no período colonial a utilização de escravos como peões era constante na capitania de São Pedro nas grandes estâncias.

Nas grandes estâncias, os escravos campeiros, especializados, supriram as necessidades de mão de obra permanentes da atividade pecuária. Trabalhavam comandados por um capataz livre [...] e certamente acompanhados de peões livres, nos momentos de pico sazonal da atividade pecuária.

Investigando a fronteira sul durante o Século XIX, Farinatti (2010, p. 357) demonstrou que os escravos campeiros constituíam a maioria nos plantéis dos grandes estancieiros, mas que "marcavam presença também 
nos extratos inferiores da hierarquia econômica dos criadores de gado."

Embora pudessem exercer funções múltiplas no complexo de uma estância, o principal trabalho do cativo campeiro consistiu em "vigiar o gado, domesticá-lo, aproximá-lo do laço e da faca" (CESAR, 2005, p. 116). Daí surgiu a expressão parar rodeio. Parar rodeio consistia em reunir tropas para contar e marcar os animais, curar e dar sal ao gado, castrar potros e touros, tosar éguas, apartar novilhos e vacas para tropear para matadouros e charqueadas (JACQUES, 2000, p. 81).

Mas além do trabalhador feitorizado, as estâncias também se valiam da força de trabalho livre permanente ou temporária. $\mathrm{Na}$ tabela 8, aparecem os salários mensais pagos a um capataz e a 12 posteiros no trimestre que vai de julho a setembro do ano de 1881 .

Tabela 8 - Lista de pagamento de salários da Estância das Pederneiras, de julho a setembro de 1881

\begin{tabular}{l|l|c|c|c}
\hline \multicolumn{1}{c|}{ Função } & \multicolumn{1}{c|}{ Nome } & tempo & valor mensal & total \\
\hline Capataz & Braz Pinto de Miranda & 3 meses & $50 \$ 000$ & $150 \$ 000$ \\
Posteiros & Tristão Vicente da Silveira & 3 meses & $12 \$ 000$ & $36 \$ 000$ \\
Posteiros & Vicente Nunes Doravel & 3 meses & $12 \$ 000$ & $36 \$ 000$ \\
Posteiros & João da Roza & 3 meses & $12 \$ 000$ & $36 \$ 000$ \\
Posteiros & Patricio Angelo Silveira & 3 meses & $12 \$ 000$ & $36 \$ 000$ \\
Posteiros & Gaspar Correa da Figueira & 3 meses & $12 \$ 000$ & $36 \$ 000$ \\
Posteiros & Antonio Candido Maciel & 3 meses & $12 \$ 000$ & $36 \$ 000$ \\
Posteiros & Fausto Salaves dos Santos & 3 meses & $12 \$ 000$ & $36 \$ 000$ \\
Posteiros & Paulino Pereira dos Santos & 3 meses & $12 \$ 000$ & $36 \$ 000$ \\
Posteiros & Hildebrando Pereira dos Santos & 3 meses & $12 \$ 000$ & $36 \$ 000$ \\
Posteiros & João Tristão da Silveira & 3 meses & $12 \$ 000$ & $36 \$ 000$ \\
Posteiros & Vicente Pinto da Miranda & 3 meses & $12 \$ 000$ & $36 \$ 000$ \\
Posteiros & Camilo Pinto de Miranda & 3 meses & $12 \$ 000$ & $36 \$ 000$ \\
\hline Total & & & $546 \$ 000$
\end{tabular}

Fonte: Inventário vereador José Ferreira Porto, 1882, p. 52.

O capataz da estância, Braz Pinto de Miranda, recebia $50 \$ 000$ ao mês. Cada um dos 12 posteiros tinha um vencimento que era de $10 \$ 000$ ou de $12 \$ 000$ mensais. Nas estâncias, os posteiros eram indispensáveis na vigilância sobre o gado. Viviam com suas famílias em ranchos na periferia da propriedade rural, em pontos nevrálgicos, - passos e encruzilhadas -, fiscalizando o trânsito dos animais, cuidado dos tapumes, tratando de substituir o olhar do dono, "multiplicando-se, onipresente, pelos campos afora" (CESAR, 2005, p. 113).

Considerando que uma rês de gado de criar valia então $13 \$ 00$, o pagamento de um posteiro ficava próximo de uma rês ao mês. Já o capataz recebia o equivalente a quatro reses mensalmente.

Na Estância das Pederneiras havia 12 escravos campeiros. Em média, a cada um deles foi atribuído o valor de 700\$000. Con- 
siderando que um posteiro ganhava entre 120 e $144 \$ 00$ anuais, conclui-se que em 4,8 a 5,8 anos de trabalho ganhava o equivalente ao preço de um escravo campeiro. O preço mensal de um posteiro equivalia, mais ou menos, a de um peão campeiro.
No inventário do vereador José Ferreira Porto aparece uma relação, datada do ano de 1882, de pagamentos feitos ao capataz, posteiros e peões da Fazenda da Cria, localizada então no município de Porto Alegre, e que possuía dez escravos.

Tabela 9 - Vencimentos pagos a trabalhadores livres da Estância da Cria em 1882

\begin{tabular}{l|l|c|c|c}
\hline \multicolumn{1}{c|}{ Função } & \multicolumn{1}{|c|}{ Nome } & tempo & valor mensal & total \\
\hline Capataz & & 3 meses & $50 \$ 000$ & $150 \$ 000$ \\
Posteiros & Bento & 3 meses & $12 \$ 000$ & $36 \$ 000$ \\
Peões & José Roberto & 3 meses & $12 \$ 000$ & $36 \$ 000$ \\
Peões & Felippe & 3 meses & $12 \$ 000$ & $36 \$ 000$ \\
Peões & Antonio & 1 meses & $12 \$ 000$ & $12 \$ 000$ \\
Peões & Angelico & 3 meses & $12 \$ 000$ & $36 \$ 000$ \\
Peões & Feliciano & 3 meses & $12 \$ 000$ & $36 \$ 000$ \\
Peões & João Ferreira & 3 meses & $12 \$ 000$ & $36 \$ 000$ \\
Peões & João Miranda & 2 meses & $12 \$ 000$ & $20 \$ 000$ \\
Peões & Hilário Gonçalves & 2 meses & $10 \$ 000$ & $20 \$ 000$ \\
\hline Total & \multicolumn{3}{|c}{} \\
\hline
\end{tabular}

Fonte: Inventário vereador José Ferreira Porto, 1882 p.32.

Como pode ser observado, o preço mensal pago ao capataz e aos posteiros da Fazenda da Cria era exatamente o mesmo que o pago aos trabalhadores livres da Estância das Pederneiras. Os peões recebiam então uma remuneração que variava entre $10 \$ 000 \mathrm{e}$ $12 \$ 000$, ou seja, semelhante ao dos posteiros.

A partir desses dados, conclui-se que, para o estancieiro, possivelmente era altamente vantajosa a utilização do trabalhador cativo. Possuir escravos parece ter sido um bom negócio para os estancieiros. Como afirma Cesar, "ficava mais em conta do que despender dinheiro indefinidamente com os assalariados" (CESAR, 2005, p. 114).

Apesar da existência de trabalhadores livres, a presença de cativos nas estâncias, exercendo atividades pastoris parece ter sido imprescindível. Formavam, ao menos nas estâncias maiores, um núcleo de trabalhadores estável e permanente da qual o estancieiro podia se valer ao longo de todo o ano (MAESTRI, 2008, p. 256). Ao mesmo tempo, a existência do trabalhador cativo deve ter atuado para deprimir as exigências e o poder de barganha dos peões e posteiros. Peões e posteiros, embora juridicamente livres, em função da existência do instituto da escravidão, submetiam-se a relações de trabalho semisservis. Assim, o ideal para um estancieiro era possuir um quadro misto de trabalhadores, mesclando livres e cativos. Caso o escravo fosse descartado e substituído apenas por trabalhadores assalariados para fazer a lida 
do campo, havia o risco de faltar mão de obra e os salários subir, já que a procura poderia exceder a oferta.

Talvez seja de bom alvitre, ao se discutir sobre as relações de trabalho no Século XIX, lembrar-se da constatação de Louis Couty (1988, p. 68), viajante francês que esteve no Brasil no final daquele mesmo século: “[...] se é fácil suprimir o escravo, ninguém sabe como organizar o trabalho livre."

\section{Considerações finais}

A partir dos dados coletados nos inventários de Mathias José Velho e de José Ferreira Porto, respectivamente proprietários, no final do Século XIX, da Estância da Nossa Senhora da Vitória e da Estância das Pederneiras, ambas então localizadas no município de Rio Pardo, RS, foi possível chegar a uma série de constatações.

No que diz respeito à composição do patrimônio produtivo dos estancieiros pesquisados, apurou-se que ele não era homogêneo. Nas Estância da Vitória, a terra se constituiu no principal bem patrimonial. Nessa unidade de produção, a propriedade da terra correspondeu a $61,97 \%$ do conjunto dos bens inventariados na estância. Já na Estância das Pederneiras a terra correspondeu a $44,55 \%$ do total patrimonial. Os animais formaram o bem mais valioso na Estância das Pederneiras, com 51,1\%. Na Estância Nossa Senhora da Vitória representaram 29,23\%.

Os cativos estiveram presentes inicialmente nas duas estâncias estudadas. Sua força de trabalho foi de grande importância nas propriedades rurais. Constituíam-se, igualmente, em uma mercadoria valiosa para os estancieiros. Na Estância da Vitória, que possuía 53 escravos, correspondiam a 7,94\% na composição do patrimônio da unidade produtiva. Na Estância das Pederneiras havia 18 escravos, equivalendo a 2,19\% do montante patrimonial. A extinção do trabalho compulsório deve ter provocado aumento nos custos de produção do gado em função do encarecimento da mão de obra. Mas isso é apenas uma hipótese que se pode levantar e que futuras pesquisas podem confirmar ou desmentir.

Ao lado dos escravos, que eram a principal força de trabalho das estâncias de criação de gado pesquisadas, havia também a presença de trabalhadores juridicamente livres. Nos inventários, eles aparecem exercendo os trabalhos de capataz, posteiro e peões. Na Estância das Pederneiras, constatou-se a presença de 13 trabalhadores livres no período de julho a setembro de 1881, entre eles um capataz e 12 posteiros. No trimestre seguinte, esse quadro de trabalhadores teve o acréscimo de mais dois posteiros.

Os trabalhadores livres - posteiros e peões - recebiam então uma remuneração que variava entre $10 \$ 000$ a $12 \$ 000$. Já os capatazes tinham uma remuneração mensal de $50 \$ 000$. Nessa mesma época, aquele que se considerava ser um bom escravo campeiro, valia $900 \$ 000$. Em média um escravo campeiro custava $700 \$ 000$. A partir desses dados se pode concluir que, para o estancieiro, possivelmente era altamente vantajosa a utilização do trabalhador cativo.

Portanto, pode-se afirmar, com algum grau de segurança, que as estâncias de Rio Pardo, durante o Século XIX, mesclavam trabalhadores cativos e livres, com a predo- 
minância dos primeiros. Assim, não se sustenta a tese longamente difundida de que na criação de gado dos campos do RS não se empregava o trabalho escravo.

\section{Abstract}

The objective of the article is to analyze the composition of the assets of livestock ranches in Rio Pardo, RS, in the late 19th century and to find out the extent to which slave labor was present in pastoral activities. For analytical focus two major farms of the county, Nossa Senhora da Vitória and Pederneiras, were chosen. The main empirical research source used consists of original manuscripts. These references are the postmortem inventories of Mathias José Velho, owner of the Santa Vitória ranch and of council member José Ferreira Porto, owner of Pederneiras.

Keywords: Livestock Ranches. Slavery. Postmortem Inventories.

\section{Abstracto}

El objetivo de este trabajo es analizar como se componia el patrimonio de las Estancias de criación de ganado en Rio Pardo, RS, al final del siglo XIX y detectar en que medida la fuerza del trabajo esclavo estuvo presente en las actividades pastoriles. Como foco de análisis fueron seleccionadas las estancias de Nossa Senhora da Vitória y de las Pederneiras, dos de los principales emprendimientos de criación del municipio. La principal fuente empirica de pesquiza utilizada fue baseada en manuscritos e inventários post mortem del Sr Mathias
José Velho, propietário de la estáncia Santa Vitoria y del Ministro Jose Ferreira Porto, dueño de las Pederneiras.

Palabras clave: Estancias de criación de ganado. Esclavitud. Publique inventarios mortem.

\section{Referências}

CARDOSO, Fernando Henrique. Capitalismo e escravidão no Brasil meridional: o negro na sociedade escravocrata do Rio Grande do Sul. Rio de Janeiro, Civilização Brasileira, 2003.

CASTRO, Antônio Barros de. Em torno à questão das técnicas no escravismo. Estudos Sociedade e Agricultura. Rio de Janeiro, v. 19, n. 2, 2011. p. 231-256.

CESAR, Guilhermino. Origens da economia gaúcha (o boi e o poder). Porto Alegre: IEL: Corag, 2005.

CHALHOUB, Sidney; SILVA, Fernando Teixeira da. Sujeitos no imaginário acadêmico: escravos e trabalhadores na historiografia brasileira desde os anos 1980. Cadernos AEL, v. 14, n. 26, 2009.

COUTY, Louis. Escravidão no Brasil. Rio de Janeiro: Fundação Casa de Rui Barbosa, 1988.

DAUMARD, Adeline et al. História social do Brasil: teoria e metodologia. Curitiba: Editora da UFPR, 1984.

EIFERT, Maria Beatriz Chini. Marcas da escravidão nas fazendas pastoris de Soledade (1867-1883). Passo Fundo: UPF Editora, 2007.

EU, Gastão de Orléans. Viagem militar ao Rio Grande do Sul. Belo Horizonte: Itatiaia, 1981.

FARINATTI, Luiz Augusto. Confins meridionais: famílias de elite e sociedade agrária na fronteira sul do Brasil (1825-1865). Santa Maria: Ed. da UFSM, 2010. 
FLEXOR, Maria Helena Ochi. Inventários e testamentos como fontes de pesquisa. In: A pesquisa e a preservação de arquivos e fontes para a educação, cultura e memória. Campinas: Alínea, 2009. p. 25-35.

FORTES, Amyr Borges. Compêndio de História do Rio Grande do Sul. Porto Alegre: Livraria Sulina, 1962.

FURTADO, Júnia Ferreira. A morte como testemunho da vida. In: PINSKY, Carla Bassanezi; LUCA, Tania Regia de (Orgs.). O historiador e suas fontes. São Paulo: Contexto, 2009. p. 93-118.

FREITAS, Décio. Escravos e senhores de escravos. Porto Alegre: Mercado Aberto, 1983.

FRANCO, Sérgio da Costa. A campanha. In: PRADO, Áurea (Coord.). Rio Grande do Sul: terra e povo. Porto Alegre: Globo, 1969. p. 65-74. GOULART, Jorge Salis. A formação do Rio Grande do Sul. Porto Alegre: EST/Martins Livreiro; Caxias do Sul: UCS, 1978.

KÜHN, Fábio. Gente fronteiriça: família, sociedade e poder no sul da América Portuguesa - século XVIII. Tese (Doutorado em História), Universidade Federal Fluminense, Niterói, 2006.

HERRLEIN JR, Ronaldo. Rio Grande do Sul 1889-1930: um outro capitalismo no Brasil meridional? Tese (Doutorado em Economia) - Universidade Estadual de Campinas, Campinas, 2000.

JACQUES, João Cezimbra. Ensaios sobre os costumes do Rio Grande do Sul: precedido de uma ligeira descrição física e de uma noção histórica. Santa Maria Ed. UFSM, 2000.

LAYTANO, Dante de. Guia histórico de Rio Pardo. Prefeitura Municipal de Rio Pardo, 2. ed. 1979.

MACEDO, Francisco Riopardense de. A Arquitetura. In: PRADO, Áurea (Coord.). Rio Grande do Sul: terra e povo. Porto Alegre: Globo, 1969. p. 109-128.
MAESTRI, Mário. O cativo, o gaúcho e o peão: considerações sobre a fazenda pastoril rio-grandense (1680-1964). In: MAESTRI, Mário (Org.). O negro e o gaúcho: estâncias e fazendas no Rio Grande do Sul, Uruguai e Brasil. Passo Fundo: UPF Editora, 2008.

MATHEUS, Marcelo Santos. Fronteiras da Liberdade: escravidão, hierarquia social e alforria no extremo sul do Império do Brasil. São Leopoldo: Oikos; Ed. Unisinos, 2012.

NOGUERÓL et al. Disponível em: <http:// www.anpec.org.br/encontro2007/artigos/ A07A025.pdf>. Acessado em: 4 fev. 2014.

OSÓRIO, Helen. O império português no sul da América: estancieiros, lavradores e comerciantes. Porto Alegre: Ed. UFRGS, 2007.

PERUSSATTO, Melina Kleinert. Como se de ventre livre nascesse: experiências de cativeiro, parentesco, emancipação e liberdade nos derradeiros anos da escravidão - Rio Pardo, RS, 1860-1888. Dissertação (Mestrado em História) - Universidade do Vale do Rio dos Sinos (Unisinos), São Leopoldo, 2010.

PINTO, Lourdes Noronha. Antigas fazendas do Rio Grande do Sul. Porto Alegre: Grafi-offset, 1989.

REVEL, Jacques (Org.). Jogos de Escalas: a experiência da microanálise. Rio de Janeiro: Fundação Getúlio Vargas Editora, 1998.

ROCHA, Antônio Penalves. As observações de Jean-Baptiste Say sobre a escravidão. Estudos Avançados, v. 14, n. 38, 2000. p. 181-212.

SAY, Jean-Baptiste. Tratado de economia política. São Paulo: Abril Cultural, 1983.

SMITH, Adam. A riqueza das nações: investigação sobre sua natureza e suas causas. São Paulo: Abril Cultural, 1983.

SOUZA DOCCA, Emílio Fernandes de. História do Rio Grande do Sul. Rio de Janeiro: Edição da Organização Simões, 1954. 
SPENNER, Bruna Vieira. Arquitetura, gado e cativo: estâncias pastoris em Rio Pardo no final do século XIX. Dissertação (Mestrado em Desenvolvimento Regional) - Universiade de Santa Cruz Santa Cruz do Sul, Santa Cruz Santa Cruz do Sul , 2013.

XAVIER, Paulo. A estância. In: PRADO, Áurea (Coord.). Rio Grande do Sul: terra e povo. Porto Alegre: Globo, 1969. p. 75-87.

ZARTH, Paulo Afonso. A importância dos arquivos do poder judiciário para a pesquisa histórica. História Social, Campinas-SP, n. 21, p. 13-35, jul./dez. 2011.

ZARTH, Paulo Afonso. História Agrária do Planalto Gaúcho. Ijuí: Editora da Uniujuí, 1997.

ZARTH, Paulo Afonso. Do arcaico ao moderno: o Rio Grande do Sul agrário no século XIX. Ijuí: Ed. Unijuí, 2002. 